\title{
A three-layer PMMA electrophoresis microchip with Pt microelectrodes insulated by a thin film for contactless conductivity detection $\dagger$
}

\author{
Junshan Liu, ${ }^{* a}$ Junyao Wang, ${ }^{a}$ Zuanguang Chen, ${ }^{b}$ Yong Yu, ${ }^{c}$ Xiujuan Yang, ${ }^{b}$ Xianbin Zhang, ${ }^{a} \mathrm{Zheng} \mathrm{Xu}^{a}$ \\ and Chong $\mathrm{Liu}^{a}$
}

Received 25th August 2010, Accepted 25th November 2010

DOI: 10.1039/c0Ic00341g

\begin{abstract}
A three-layer poly (methyl methacrylate) (PMMA) electrophoresis microchip integrated with $\mathrm{Pt}$ microelectrodes for contactless conductivity detection is presented. A $50 \mu \mathrm{m}$-thick PMMA film is used as the insulating layer and placed between the channel plate (containing the microchannel) and the electrode plate (containing the microelectrode). The three-layer structure facilitates the achievement of a thin insulating layer, obviates the difficulty of integrating microelectrodes on a thin film, and does not compromise the integration of microchips. To overcome the thermal and chemical incompatibilities of polymers and photolithographic techniques, a modified lift-off process was developed to integrate $\mathrm{Pt}$ microelectrodes onto the PMMA substrate. A novel two-step bonding method was created to assemble the complete PMMA microchip. A low limit of detection of $1.25 \mu \mathrm{g} \mathrm{ml}^{-1}$ for $\mathrm{Na}^{+}$and high separation efficiency of 77000 and 48000 plates $/ \mathrm{m}$ for $\mathrm{Na}^{+}$and $\mathrm{K}^{+}$were obtained when operating the detector at a low excitation frequency of $60 \mathrm{kHz}$.
\end{abstract}

\section{Introduction}

Conductivity detection is considered a simple and universal detection method, and has been widely applied in electrophoresis microchips. ${ }^{1-7}$ Conductivity detection can be classified into two modes: contact mode and contactless mode. In contact mode, the microelectrode directly contacts the solution. ${ }^{1,2}$ In contactless mode, the microelectrode is insulated from the solution by an insulating layer. ${ }^{3-7}$ Compared with contact mode, contactless mode has several advantages because of the insulation of the electrode from the solution, such as the elimination of electrode fouling, bubble generation, and the isolation from the separation voltage. $^{3-7}$

It has been shown that the thickness of the insulating layer is one of the important parameters influencing the sensitivity of contactless conductivity detection (CCD), where generally microchips with a thin insulating layer are desirable. ${ }^{8-10}$ Guijt first introduced the CCD in electrophoresis microchips. ${ }^{11}$ Aluminium microelectrodes were incorporated into the separation channel and insulated from the solution by covering a 30

${ }^{a}$ Key Laboratory for Micro/Nano Technology and System of Liaoning Province, Dalian University of Technology, Dalian, Liaoning, 116023, China.E-mail: liujs@dlut.edu.cn

${ }^{b}$ School of Pharmaceutical Sciences, Sun Yat-sen University, Guangzhou, Guangdong, 510089, China. E-mail: chenzg@mail.sysu.edu.cn

${ }^{c}$ National Microgravity Laboratory, Institute of Mechanics, Chinese Academy of Sciences, Beijing, 100190, China.E-mail: yuyong@imech.ac. cn

$\dagger$ Electronic supplementary information (ESI) available: Supplementary Fig. S1. See DOI: $10.1039 / \mathrm{c} 01 \mathrm{c} 00341 \mathrm{~g}$ nm-thick silicon carbide layer. Lichtenberg structured $\mathrm{Pt}$ microelectrodes into a recess, and a $10 \mu \mathrm{m}$-thick glass wall isolated the recess from the separation channel. ${ }^{12}$ Although these two methods can be used to achieve very thin insulating layers, the fabrication of microchips is complicated.

Pumera placed the microelectrode on the outer side of a $125 \mu \mathrm{m}$-thick PMMA electrode plate (containing the microelectrode). ${ }^{13}$ That is, the electrode plate also acted as the insulating layer, which makes the fabrication of microchips much simpler and therefore has been widely accepted. ${ }^{14,15}$

Although placing the microelectrode on the outer side of the electrode plate facilitates the fabrication of microchips, constructing this kind of microchip with a very thin insulating layer (less than $100 \mu \mathrm{m}$ ) still remains a challenge. For example, thin films made of glass are fragile, and those made of polymers are prone to curving and deforming, thus being difficult to integrate with microelectrodes. Kubán and Hauser placed the microelectrode on a separate electrode plate, and had the electrode plate in tight contact with the thin cover plate of a PMMA microchip. ${ }^{8,16}$ Chen $^{9}$ and Vázquez ${ }^{10}$ employed a similar technique to fabricate glass and hybrid PDMS-glass microchips. While this method didn't require integrating microelectrodes on a thin film, the microelectrode was not fully integrated onto the chip and some assistant structures were needed, such as chip holders, screws or clips, which compromised the integration and reproducibility of the microchips. Moreover, to our knowledge, the smallest thickness of the thin cover plate thus far is $100 \mu \mathrm{m} .^{9}$

In this note, we introduce a novel three-layer electrophoresis microchip integrated with $\mathrm{Pt}$ microelectrodes for the CCD. A 
$50 \mu \mathrm{m}$-thick PMMA film is used as the insulating layer, and we describe a novel two-step bonding method for bonding the film with the PMMA channel plate (containing the microchannel) and the PMMA electrode plate successively to make a complete PMMA microchip. The three-layer structure facilitates the achievement of a thin insulating layer, obviates the difficulty of integrating microelectrodes on a thin film, and does not compromise the manufacturing simplification and integration of the microchip.

\section{Experimental}

\section{Design of the microchip}

The three-layer PMMA electrophoresis microchip shown in Fig. 1 is composed of a PMMA channel plate $(45 \times 80 \times 2 \mathrm{~mm})$, a PMMA film $(45 \times 80 \times 0.05 \mathrm{~mm})$ and a PMMA electrode plate $(60 \times 80 \times 2 \mathrm{~mm})$. The separation channel is $90 \mu \mathrm{m}$ wide, $30 \mu \mathrm{m}$ deep and $45 \mathrm{~mm}$ long. Two microelectrodes are placed in an antiparallel orientation, with a gap between them of $0.7 \mathrm{~mm}$. Each of these two microelectrodes is $0.8 \mathrm{~mm}$ wide and $10 \mathrm{~mm}$ long, and the width of the end is $4 \mathrm{~mm}$ to facilitate the electrical connection.

\section{Fabrication of Pt microelectrodes}

The Pt microelectrode for the CCD was fabricated by using a liftoff process, which is schematically depicted in Fig. 2: (a) A positive photoresist (BP212, Beijing Institute of Chemical Reagents, China) was spin-coated on the PMMA surface at 2600 rpm for $30 \mathrm{~s}$. (b) The photoresist was soft-baked and exposed to UV light at a dose of $4.2 \mathrm{~mJ} \mathrm{~cm} \mathrm{c}^{-2}$ for $30 \mathrm{~s}$ through a photomask. (c) The photoresist was developed in $0.5 \% \mathrm{NaOH}$ solution. (d) The photoresist was secondly exposed to UV light for $3 \mathrm{~min}$ without a photomask. (e) A thin Ti layer (20-30 nm) was sputtered on the PMMA surface, followed by a Pt layer $(80-100 \mathrm{~nm})$ at a sputtering power of $150 \mathrm{~W}$. (f) The PMMA plate was placed in $0.5 \% \mathrm{NaOH}$ solution to remove the residual photoresist which was coated by unwanted $\mathrm{Ti}$ and $\mathrm{Pt}$.
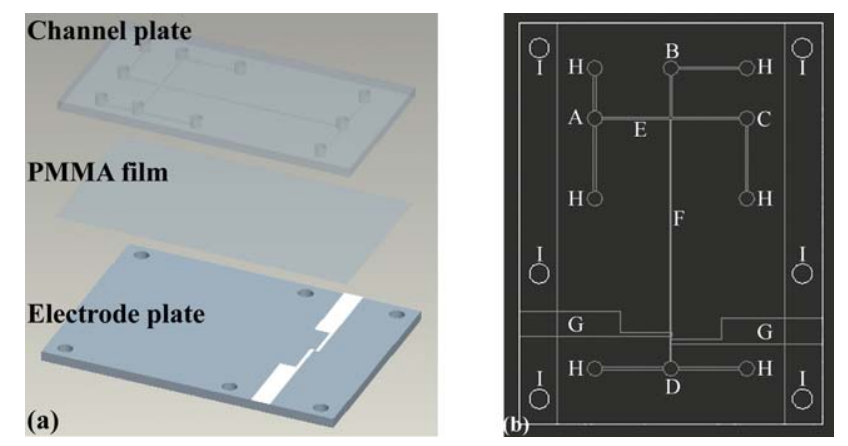

Fig. 1 (a) Layout of the three-layer microchip; (b) Top view of the microchip. A sample reservoir, B buffer reservoir, C sample waste reservoir, D buffer waste reservoir, $\mathrm{E}$ injection channel, $\mathrm{F}$ separation channel, G microelectrodes, $\mathrm{H}$ reservoirs not used, I holes not used.

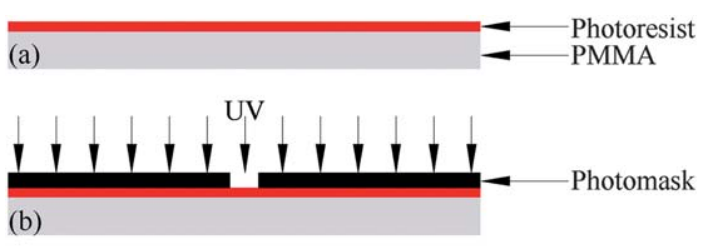

(c)

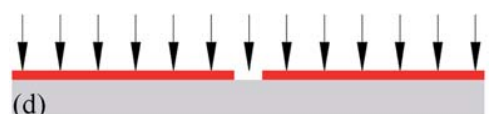

(d)

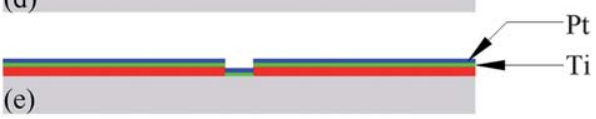

(f)

Fig. 2 Fabrication of the Pt microelectrode. (a) Spin-coating of the photoresist; (b) First exposure of the photoresist; (c) Developing of the photoresist; (d) Second exposure of the photoresist; (e) Sputtering of Ti and Pt layers; (f) Removing of the residual photoresist.

\section{Fabrication of the microchannel}

The microchannel was fabricated based on previously published procedures. ${ }^{17}$ Briefly, a Si mould was fabricated by lithography and wet chemical etching. A PMMA plate was placed on the $\mathrm{Si}$ mould and embossed at $110{ }^{\circ} \mathrm{C}$ and under a pressure of $1.4 \mathrm{MPa}$ for $5 \mathrm{~min}$ by using a home-made embossing machine. The control accuracies of the pressure and the temperature of this embossing machine are $20 \mathrm{~N}$ and $0.2^{\circ} \mathrm{C}$, respectively. The PMMA plate and the Si mould were cooled down to $65^{\circ} \mathrm{C}$ and separated. Finally, access holes for fluidic connections were drilled.

\section{Assembly of the microchip}

The assembly of the microchip was accomplished by a two-step thermal bonding process. A home-made embossing machine was also used for the thermal bonding.

First, the $50 \mu \mathrm{m}$-thick PMMA film was bonded with the PMMA channel plate at $100^{\circ} \mathrm{C}$, under a pressure of $1.2 \mathrm{MPa}$ for $5 \mathrm{~min}$. Then, the outer side of the PMMA film was exposed to $\mathrm{O}_{2}$ plasma for 2 min with a RF power of $60 \mathrm{~W}$ and a chamber pressure of $200 \mathrm{~Pa}$ by using a plasma cleaner (DQ-500, China Electronics Technology Group Corporation, China). Finally, the outer side of the PMMA film was bonded with the electrode plate at $85{ }^{\circ} \mathrm{C}$, under a pressure of $1.2 \mathrm{MPa}$ for $5 \mathrm{~min}$, to make the whole microchip (Fig. 3).

\section{Reagents and electrophoresis procedures}

All reagents were of analytical grade. 2-( $N$-Morpholino)ethanesulfonic acid (MES) was purchased from AMRES Co. (Hong Kong, China). Histidine (His) was obtained from Shanghai Bio Life Science \& Technology Co. Ltd. (Shanghai, China). Potassium chloride and sodium chloride were obtained from Damao Chemical Reagent Factory (Tianjin, China). All remaining reagents were purchased from Guangzhou Chemical Reagent Co. (Guangzhou, China). Buffer solutions and stock sample 


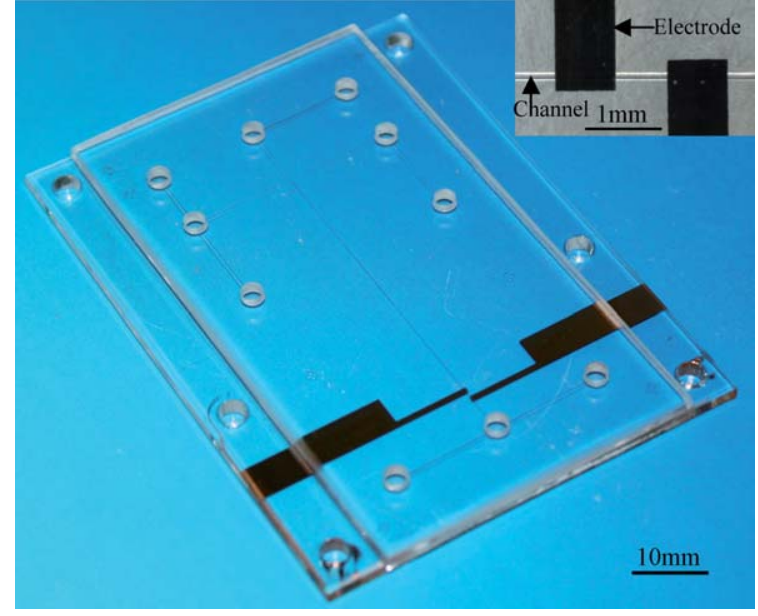

Fig. 3 The three-layer PMMA electrophoresis microchip integrated with Pt microelectrodes. The enlarged view of the microelectrode and the microchannel region is shown in the inset.

solution were prepared with redistilled water in $0.1 \mathrm{~mol} \mathrm{~L}^{-1}$, and operating sample solutions were diluted from the stock sample solution by running buffer solutions prior to use. All solutions were filtered by a $0.2 \mu \mathrm{m}$ filter membrane before being injected into the microchip.

We used a home-made high voltage supplier, which can provide potential-constant direct currents of $100-500 \mathrm{~V}$ for the injection and $500-5000 \mathrm{~V}$ for the separation process. The homemade contactless conductivity detector was described previously. ${ }^{18}$ Prior to use the channels were flushed with $0.1 \mathrm{~mol} \mathrm{~L}^{-1}$ sodium hydroxide aqueous solution, redistilled water, and running buffer solution for 5, 5, and $10 \mathrm{~min}$, respectively. Then, reservoirs $\mathrm{B}, \mathrm{C}$ and $\mathrm{D}$ were filled with the running buffer solution, the reservoir A was filled with sample solution, and four Pt electrodes were inserted into these four reservoirs. Electrokinetic injection was performed by applying a potential between reservoirs $A$ and $C$ while reservoirs $B$ and $D$ were floated. Separations were conducted by switching to the high voltage between reservoirs $\mathrm{B}$ and $\mathrm{D}$ while other two reservoirs were floated. The microchannel was treated as described previously following each analysis run. At the end of each set of experiments, the channel was filled with redistilled water to prevent clogging of the microchip.

\section{Results and discussion}

\section{Modification of the lift-off process}

While lift-off processes for fabricating Pt microelectrodes have been well established in the semiconductor industry, it was necessary to develop a new process due to the thermal and chemical incompatibilities of polymers and photolithographic techniques. First, although the recommended soft-baked temperature of the photoresist used in this work is $90{ }^{\circ} \mathrm{C}$ according to the manufacturer's instructions, the photoresist here was soft-baked at a lower temperature of $60^{\circ} \mathrm{C}$ for $5 \mathrm{~min}$ to avoid the thermal deformation of the PMMA plate.

Second, we replaced acetone, ${ }^{19,20}$ which is known to dissolve PMMA, with a $0.5 \% \mathrm{NaOH}$ solution when removing the residual photoresist. Third, the photoresist was secondarily exposed to
UV for a longer time in order to facilitate the removal of the photoresist by the $\mathrm{NaOH}$ solution. The residual photoresist, however, could not be removed completely, which always caused some rough edges around the microelectrode, as shown in Fig. S1(a). $\dagger$ We hypothesize that the hard-bake process affects the quality of the lift off. The hard-bake process makes the photoresist more resistant to chemical attack, but at the same time makes it reflow, resulting in rounded edges. Thus, we suggest that the metal on the photoresist tore off some of the metal on the PMMA surface when the lift off was executed. Therefore, the hard-bake process was omitted here. As shown in Fig. S1(b), $\uparrow$ Pt microelectrodes with smooth edges on PMMA substrates were obtained by using this modified lift-off process.

\section{Two-step bonding process}

Although several methods have been reported for bonding PMMA microfluidic chips, thermal bonding is especially desirable because it forms microchannels with homogeneous internal surfaces. ${ }^{21,22}$ To make the three-layer microchip by thermal bonding, there are two aspects that should be taken into account. The bonding temperature should be lowered as much as possible to avoid fractures in the metal microelectrode. ${ }^{23}$ Further, we observed that the $50 \mu \mathrm{m}$-thick PMMA film could not be bonded completely with the channel plate at a temperature below $100^{\circ} \mathrm{C}$. We addressed these issues by developing a two-step bonding method.

First, the $50 \mu \mathrm{m}$-thick PMMA film was bonded with the channel plate at $100^{\circ} \mathrm{C}$. The PMMA film is prone to curving, and cutting the film from a PMMA sheet makes the edges of the film rough, both of which can make the bonding difficult. Hence, the PMMA film was clamped between two polished glass plates and heated to $100^{\circ} \mathrm{C}$ for $5 \mathrm{~min}$ before bonding to flatten the film and smoothen the edges. Second, to lower the bonding temperature, the PMMA film was thermally bonded to the electrode plate with the help of plasma surface treatment. It has been previously demonstrated that the oxygen plasma treatment of the PMMA surface reduces the bonding temperature from $100{ }^{\circ} \mathrm{C}$ to $85^{\circ} \mathrm{C}$ while maintaining comparable bonding strength. ${ }^{23}$ Five chips

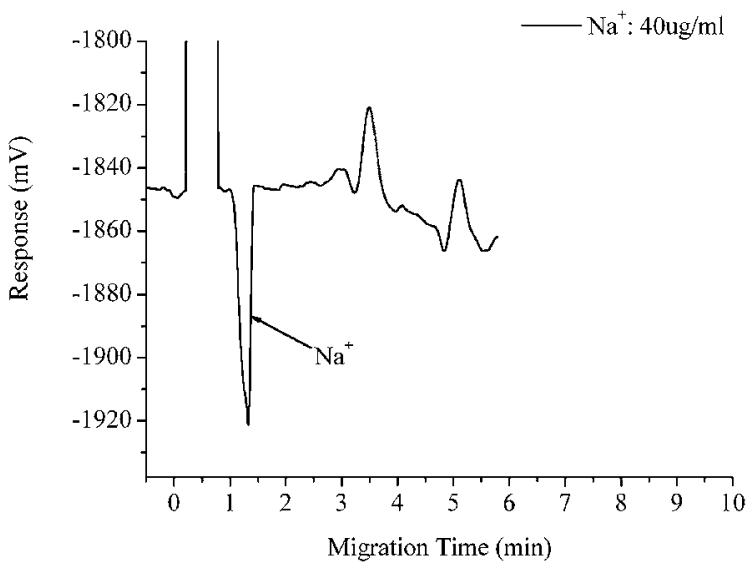

Fig. 4 The electrophorogram of $\mathrm{Na}^{+}$. Electrophoretic conditions: buffer solution, $20 \mathrm{mmol} \mathrm{L}^{-1}$ MES-20 mmol L ${ }^{-1}$ His, injection voltage $500 \mathrm{~V}$, separation voltage $1.8 \mathrm{kV}$. Excitation voltage $50 \mathrm{~V}_{\mathrm{pp}}$ and frequency $60 \mathrm{kHz}$. 
Table 1 Comparation of LOD and theoretical plate (N.R., not reported)

\begin{tabular}{|c|c|c|c|c|c|c|}
\hline Chip material & $\begin{array}{l}\text { Thickness of the } \\
\text { insulating layer/ } / \mu \mathrm{m}\end{array}$ & $\begin{array}{l}\text { Width and gap } \\
\text { of the two } \\
\text { microelectrodes } / \mathrm{mm}\end{array}$ & $\begin{array}{l}\text { Excitation } \\
\text { frequency } / \mathrm{kHz}\end{array}$ & $\begin{array}{l}\text { LOD for } \\
\mathrm{Na}^{+} / \mu \mathrm{M}\end{array}$ & $\begin{array}{l}\text { Theoretical plates for } \\
\mathrm{Na}^{+} \text {and } \mathrm{K}^{+} \text {(plates } / \mathrm{m} \text { ) }\end{array}$ & Reference \\
\hline PMMA & 50 & $0.8,0.7$ & 60 & 21 & 77000,48000 & Our group \\
\hline PMMA & 100 & $0.8,0.8$ & 200 & $>30$ & $28000-44000$ & {$[25]$} \\
\hline PMMA & 100 & $0.8,0.8$ & 200 & $>30$ & 14000,8000 & [26] \\
\hline PMMA & 125 & $1.0,0.5$ & 500 & 4 & $13000-17000$ & [8] \\
\hline
\end{tabular}

were bonded this way, and four out of the five chips presented continuous electrodes without cracks or fractures.

\section{Characteristics of the microchip}

The frequency and voltage of the sinusoidal excitation signal were optimized based on previously published procedures. ${ }^{9}$ An excitation signal of $50 \mathrm{~V}_{\mathrm{pp}}$ (peak-to-peak) and $60 \mathrm{kHz}$ were determined to be the optimal conditions and were therefore used in all experiments. The best results were obtained when the running buffer solution consisted of $20 \mathrm{mmol} \mathrm{L}^{-1} \mathrm{MES}$ and 20 mmol L${ }^{-1} \mathrm{His}$ at $\mathrm{pH}$ 6.0. The electrophorogram of $\mathrm{Na}^{+}$is shown in Fig. 4. A well-defined peak shape was achieved and the half peak width was $6.4 \mathrm{~s}$.

The sensitivity of the CCD reported here was compared with the data previously published in terms of the limit of detection (LOD) of $\mathrm{Na}^{+}$, where microchips were made of the same material (PMMA). ${ }^{8,16,24-27}$ Based on the signal-to-noise ratio of 3 , the LOD for $\mathrm{Na}^{+}$was $1.25 \mu \mathrm{g} \mathrm{ml}^{-1}$ by using our system. As expected, the LOD obtained by our chip is lower than those results obtained from chips with similar electrode geometry, thicker insulating layers and operated at low excitation frequencies, ${ }^{24-26}$ as shown in Table 1. While it is higher than the results reported by Kubán̆ and Hauser, 8,16,27 the excitation frequencies used in their work $\left(500 \mathrm{kHz},{ }^{8} 530 \mathrm{kHz},{ }^{16} 600 \mathrm{kHz}^{27}\right)$ are much higher than our applied frequency of $60 \mathrm{kHz}$ and the range of the detector $(0-300 \mathrm{kHz})$ used here, which is in line with the conclusion that the output of the detector increased sharply between 400 and $600 \mathrm{kHz} .{ }^{13}$ Moreover, the LODs in their work were obtained when the optimized electrode geometry was used, and it has also been demonstrated that the electrode geometry had a significant effect on the sensitivity. ${ }^{8,16}$ Therefore, a better sensitivity could be expected after using a new contactless conductivity detector with a wider range of excitation frequencies and optimizing the electrode geometry in the near future.

The separation efficiency of this microchip was demonstrated by the separation of $\mathrm{Na}^{+}$and $\mathrm{K}^{+}$. As shown in Fig. $5, \mathrm{Na}^{+}$and $\mathrm{K}^{+}$ were baseline separated within $50 \mathrm{~s}$ and the resolution was 2.13 . Theoretical plates for $\mathrm{Na}^{+}$and $\mathrm{K}^{+}$were 77260 and 48293 plates/ $\mathrm{m}$, respectively, which are higher than those results reported in the literature, ${ }^{8,16,24-26}$ as shown in Table 1.

\section{Conclusions}

A novel three-layer PMMA electrophoresis microchip for the CCD is presented in this study. To fabricate this complete

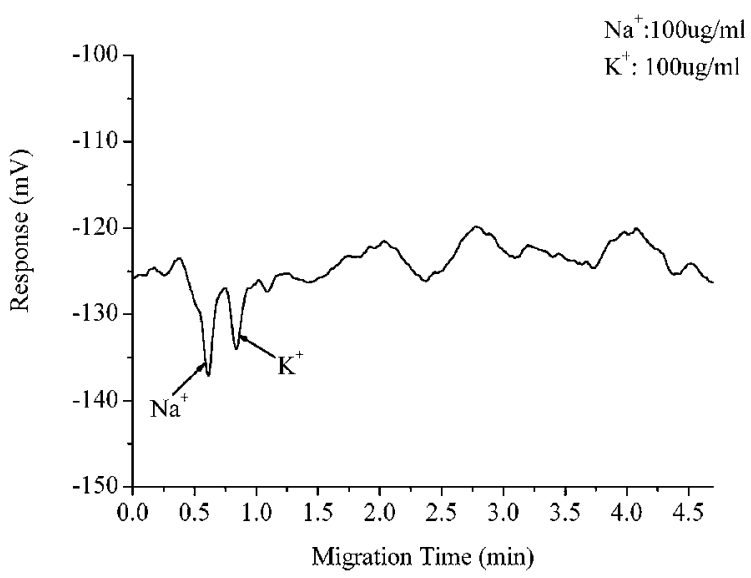

Fig. 5 The electrophorogram of the separation of $\mathrm{Na}^{+}$and $\mathrm{K}^{+}$. Electrophoretic conditions: buffer solution, $20 \mathrm{mmol} \mathrm{L}{ }^{-1}$ MES $-20 \mathrm{mmol} \mathrm{L}^{-1}$ His, injection voltage $500 \mathrm{~V}$, separation voltage $1.8 \mathrm{kV}$. Excitation voltage $50 \mathrm{~V}_{\mathrm{pp}}$ and frequency $60 \mathrm{kHz}$.

PMMA microchip, we modified the lift-off process and introduced a two-step bonding method. The sensitivity and separation efficiency of this microchip were investigated. A low LOD for $\mathrm{Na}^{+}\left(1.25 \mu \mathrm{g} \mathrm{ml}^{-1}\right)$ and high separation efficiencies for $\mathrm{Na}^{+}$ (77 000 plates $/ \mathrm{m}$ ) and $\mathrm{K}^{+}$(48 000 plates $/ \mathrm{m}$ ) were obtained when operating the conductivity detector at a much lower excitation frequency $(60 \mathrm{kHz})$. This three-layer microchip has several intrinsic advantages. First, it facilitates the achievement of thin insulating layer by bonding commercially available polymer films. Second, the difficulty of integrating metal microelectrodes on a thin film is successfully circumvented. Third, compared to microchips with an independent electrode plate, our device does not require assistant structures, such as chip holders, screws and clips, which benefits the stability and reproducibility of the microchip. Finally, the fabrication of the microchip proposed here is compatible with the microfabrication techniques, which makes the microchip suitable for low cost mass production.

\section{Acknowledgements}

This work was supported by the National Natural Science Foundation of China (50605006, 51075056, 50705012, 20890024, 20727006), and the National Basic Research Program of China (2007CB714502). We thank Yanan Du, Jason W. Nichol and Šeila Selimović for scientific discussions and revisions. J. Liu, Y. Yu, Z. Chen, Z. Xu and C. Liu designed the research strategy; 
J. Liu, J. Wang, X. Yang and X. Zhang performed the experiments; Y. Yu designed the microchip; J. Liu, J. Wang and X. Yang wrote the paper.

\section{References}

1 B. Graß, A. Neyer, M. Jöhnck, D. Siepe, F. Eisenbeiß, G. Weber and R. Hergenröder, Sens. Actuators, B, 2001, 72, 249-258.

2 M. Galloway, W. Stryjewski, A. Henry, S. M. Ford, S. Llopis, R. L. McCarley and S. A. Soper, Anal. Chem., 2002, 74, 2407-2415.

3 J. Wang, G. Chen and A. M. Jr., Anal. Chem., 2003, 75, 4475-4479.

4 F. Laugere, G. W. Lubking, J. Bastemeijer and M. J. Vellekoop, Sens. Actuators, B, 2002, 83, 104-108.

5 J. Wang, G. Chen, M. P. Chatrathi, M. Wang, R. Rinehart and A. Muck, Electroanalysis, 2008, 20, 2416-2421.

6 P. Kubán and P. C. Hauser, Anal. Chim. Acta, 2008, 607, 15-29.

7 G. Fercher, A. Haller, W. Smetana and M. J. Vellekoop, Anal. Chem., 2010, 82, 3270-3275.

8 P. Kubáň and P. C. Hauser, Lab Chip, 2005, 5, 407-415.

9 Z. G. Chen, Q. W. Li, O. L. Li, X. Zhou, Y. Lan, Y. F. Wei and J. Y. Mo, Talanta, 2007, 71, 1944-1950.

10 M. Vázquez, C. Frankenfeld, W. K. T. Coltro, E. Carrilho, D. Diamond and S. M. Lunte, Analyst, 2010, 135, 96-103.

11 R. M. Guijt, E. Baltussen, G. van der Steen, H. Frank, H. Billiet, T. Schalkhammer, F. Laugere, M. Vellekoop, A. Berthold, L. Sarro and G. W. K. van Dedem, Electrophoresis, 2001, 22, 2537-2541.
12 J. Lichtenberg, N. F. de Rooij and E. Verpoorte, Electrophoresis, 2002, 23, 3769-3780.

13 M. Pumera, J. Wang, F. Opekar, I. Jelínek, J. Feldman, H. Löwe and S. Hardt, Anal. Chem., 2002, 74, 1968-1971.

14 J. Wang and M. Pumera, Anal. Chem., 2002, 74, 5919-5923.

15 W. K. T. Coltro, J. A. F. da Silva and E. Carrilho, Electrophoresis, 2008, 29, 2260-2265.

16 P. Kubán̆ and P. C. Hauser, Lab Chip, 2008, 8, 1829-1836.

17 J. S. Liu, C. Liu, J. H. Guo and L. D. Wang, J. Mater. Process. Technol., 2006, 178, 278-282.

18 Z. G. Chen and J. Y. Mo, Chem. J. Chin. Univ, 2002, 23, 801-804.

19 S. K. Kim, H. Lim, T. D. Chung and H. C. Kim, Sens. Actuators, B, 2006, 115, 212-219.

20 X. Illa, O. Ordeig, D. Snakenborg, A. Romano-Rodríguez, R. G. Compton and J. P. Kutter, Lab Chip, 2010, 10, 1254-1261.

21 R. T. Kelly and A. T. Woolley, Anal. Chem., 2003, 75, 1941-1945.

22 M. S. Kim, S. Cho, K. N. Lee and Y. K. Kim, Sens. Actuators, B, 2005, 107, 818-824.

23 J. S. Liu, H. C. Qiao, C. Liu, Z. Xu, Y. Q. Li and L. D. Wang, Sens. Actuators, B, 2009, 141, 646-651.

24 G. Chen, J. Li, S. Qu, D. Chen and P. Yang, J. Chromatogr., A, 2005, 1094, 138-147.

25 Y. Chen, P. Yang, J. Li, D. Chen and G. Chen, Anal. Bioanal. Chem., 2006, 384, 683-691.

26 S. Qu, X. Chen, D. Chen, P. Yang and G. Chen, Electrophoresis, 2006, 27, 4910-4918.

27 P. Kubáň and P. C. Hauser, Electrophoresis, 2005, 26, 3169-3178. 